Original Research Article

\title{
Prescription pattern of fixed dose drug combinations in obstetrics and gynecology department of a tertiary care hospital in Puducherry, India: an observational study
}

\author{
Manjunatha C. H., Rohith V.*, Maheshwari R., Isabella Topno
}

Department of Pharmacology, Pondicherry Institute of Medical Sciences, Pondicherry, India

Received: 12 October 2018 Accepted: 19 October 2018

*Correspondence to:

Dr. Rohith V.,

Email: rohithv60@gmail.com

Copyright: (C) the author(s), publisher and licensee Medip Academy. This is an openaccess article distributed under the terms of the Creative Commons Attribution NonCommercial License, which permits unrestricted noncommercial use, distribution, and reproduction in any medium, provided the original work is properly cited.

\begin{abstract}
Background: Fixed drug combinations (FDCs)have various advantages and disadvantages. In countries like India there are numerous irrational prescriptions as highlighted by the recent banning of FDCs in October 2018. Studying the prescription pattern helps in developing national database which can be used to promote rational use of drugs.

Methods: All the Outdoor Patient Department (OPD) prescriptions from department of Obstetrics and Gynecology (OBG) during the study period were used for the study. The drugs were classified according to Anatomical Therapeutic Chemical (ATC) classification. Other data studied were the number of FDCs and the number of currently banned combinations which were used during the study period.

Results: The $41 \%$ of the drugs prescribed as FDCs. Most FDCs belonged to alimentary system followed by anti-infectives and blood and blood forming organs group. Vitamin D3 and Calcium combination was the most commonly prescribed FDC. Approximately $20 \%$ of these prescribed drugs are currently banned.
\end{abstract}

Conclusions: A significant number of drugs are being prescribed as FDCs which also includes various irrational combinations.

Keywords: Fixed drug combinations, Prescription, irrational, ATC classification

\section{INTRODUCTION}

The term FDC is synonymous with fixed-ratio combination. Both terms refer to a product that contains two or more active ingredients. World Health Organization (WHO) defines Fixed Dose Combinations (FDCs) as combination of two or more active ingredients in a fixed ratio of doses. ${ }^{1}$ Some advantages of fixed-dose combinations are better patient compliance and economical. They also have some disadvantage like they discourage adjustment of doses according to patient's need. ${ }^{2}$ Numerous irrational fixed drug combinations are prescribed in India. The most pressing concern with irrational FDCs is that they expose patients to unnecessary risk of adverse drug reactions. ${ }^{3}$

This study becomes even more relevant in the context that as many as 328 fixed drug combinations have been banned after a prolonged battle between pharmaceutical industry and regulatory bodies in September 2018. This shows how rampant is the menace of irrational fixed drug combination. ${ }^{4}$ Prescription pattern monitoring studies focus mainly on prescribing, dispensing and administering of drugs. They promote appropriate use of monitored 
drugs and reduction of abuse or misuse of monitored drugs. 5

Obstetrics and Gynecology (OBG) is one such department where FDCs are commonly used and there is need to monitor the prescription pattern of such FDCs to promote rational use of medications.

\section{METHODS}

This is a prospective and observational study done in a tertiary care hospital of Pondicherry institute of medical sciences, a six hundred and forty bedded hospital, in Pondicherry, India.

All the patients attending Obstetrics and Gynecology Outdoor patient department were selected.

\section{Inclusion criteria}

Prescriptions of all patients attending Obstetrics and Gynecology Outpatient department during the study period were included in this study.

\section{Exclusion criteria}

Indoor patients attending Obstetrics and Gynecology Outdoor patient department were excluded from this study.

The study was conducted during the period of April October, 2016. Patients attending Obstetrics and Gynecology Outdoor patient department from in and around Pondicherry.

A total of One thousand four hundred and eighty two prescriptions were collected and analyzed prospectively. All the Outdoor patient department Prescriptions from Obstetrics and Gynecology department over a period of 6 months were collected.

\section{Data analysis}

The data was entered, stored and evaluated using Microsoft excel 2016. Descriptive statistics was used to analyze data. The prescribed fixed dose combination drugs and other drugs were categorized according to Anatomical Therapeutic Chemical classification.

The percentage of Fixed drug combinations used in each class and their contribution to overall Fixed drug combinations were calculated. Number of Fixed drug combinations that are currently banned were also identified.

Since this is an Observational study where data was obtained using Outdoor Patient Department prescriptions of Obstetrics and Gynecology Department, without any risk associated with interventional human studies and hence there are no ethical considerations.

\section{RESULTS}

In 1482 prescriptions, a total of 2787 drugs were prescribed. Of this, 1166 were FDCs and 1621 were others. The group wise distribution of drugs, according to ATC classification and FDCs in that category, is listed in the Table 1.

Table 1: ATC Class of drugs prescribed.

\begin{tabular}{|lll|}
\hline $\begin{array}{l}\text { ATC Class of } \\
\text { drugs }\end{array}$ & FDC & Non-FDC \\
\hline Alimentary tract & $552(36.70 \%)$ & $952(63.3 \%)$ \\
\hline $\begin{array}{l}\text { Blood and blood } \\
\text { forming organs }\end{array}$ & $49(13.53 \%)$ & $313(86.47 \%)$ \\
\hline CVS & $0(00.00 \%)$ & $6(100 \%)$ \\
\hline Dermatology & $1(16.66 \%)$ & $5(83.34 \%)$ \\
\hline Genitourinary & $38(19.89 \%)$ & $153(80.11 \%)$ \\
\hline Systemic hormones & $0(00.00 \%)$ & $21(100.00 \%)$ \\
\hline Anti-infective & $188(47.95 \%)$ & $204(52.05 \%)$ \\
\hline Musculoskeletal & $29(72.50 \%)$ & $11(27.50 \%)$ \\
\hline Nervous system & $69(72.63 \%)$ & $26(27.37 \%)$ \\
\hline Anti-parasitic & $0(00.00 \%)$ & $79(100.00 \%)$ \\
\hline Respiratory system & $49(55.68 \%)$ & $39(44.32 \%)$ \\
\hline Others & $1(33.33 \%)$ & $2(66.67 \%)$ \\
\hline
\end{tabular}

The highest percentage of FDCs were seen in Alimentary tract and metabolism (56.61\%), followed by anti-infective (19.28\%), Nervous system (07.07\%), Blood and blood forming organs $(05.02 \%)$ and Respiratory system $(05.02 \%)$ as shown in the Table 2.

Table 2: Percentage of different FDCs prescribed.

\begin{tabular}{|lll|}
\hline ATC Class of drugs & FDC & Percentage \\
\hline Alimentary tract & 552 & $56.61 \%$ \\
\hline $\begin{array}{l}\text { Blood and blood forming } \\
\text { organs }\end{array}$ & 49 & $05.02 \%$ \\
\hline CVS & 0 & $00.00 \%$ \\
\hline Dermatology & 1 & $00.102 \%$ \\
\hline Genitourinary & 38 & $03.89 \%$ \\
\hline Systemic hormones & 0 & $00.00 \%$ \\
\hline Anti-infective & 188 & $19.28 \%$ \\
\hline Musculoskeletal & 29 & $02.97 \%$ \\
\hline Nervous system & 69 & $07.07 \%$ \\
\hline Anti-parasitic & 0 & $00.00 \%$ \\
\hline Respiratory system & 49 & $05.02 \%$ \\
\hline Others & 1 & $00.102 \%$ \\
\hline
\end{tabular}

Among drugs affecting the Alimentary system, the most common FDC was a combination of Vitamin D3 and Calcium $(97.46 \%)$ followed by antacid combination of Oxethazaine+ magnesium hydroxide+aluminium hydroxide $(0.90 \%)$ and Ascorbic acid + sodium ascorbate $(0.04 \%)$ as shown in the Figure 1. 


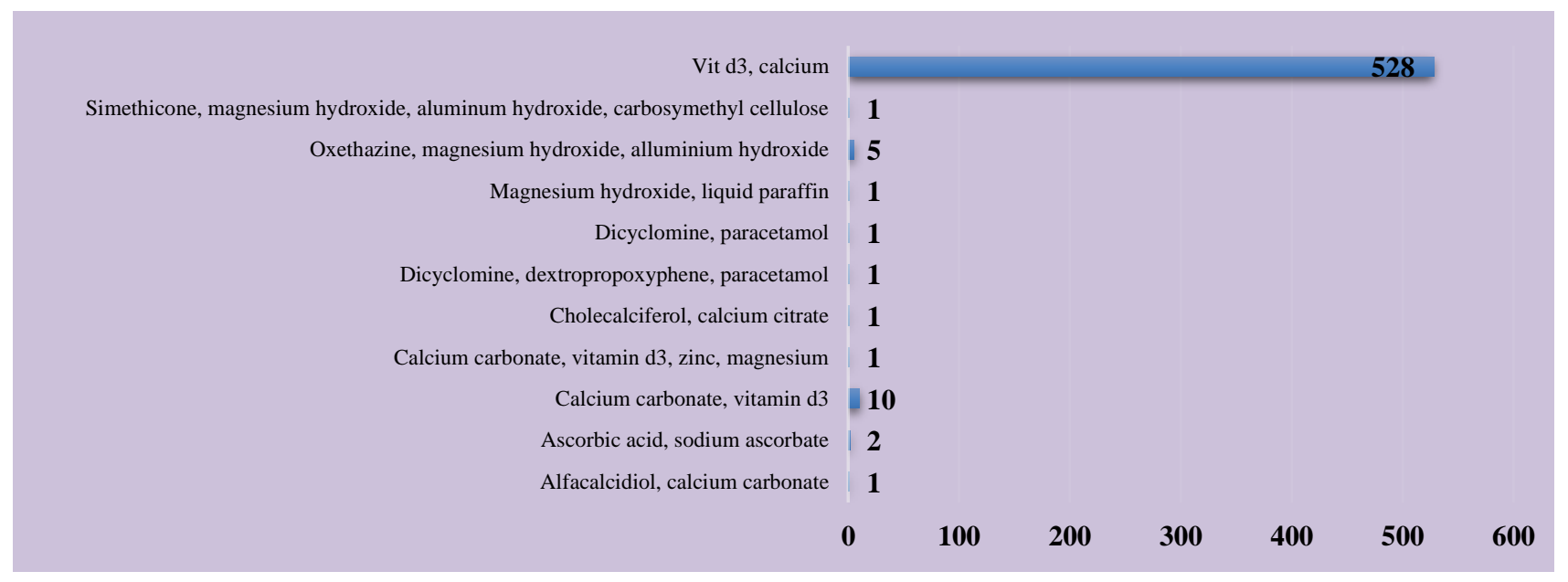

Figure 1: Number of different FDCs prescribed in alimentary system.

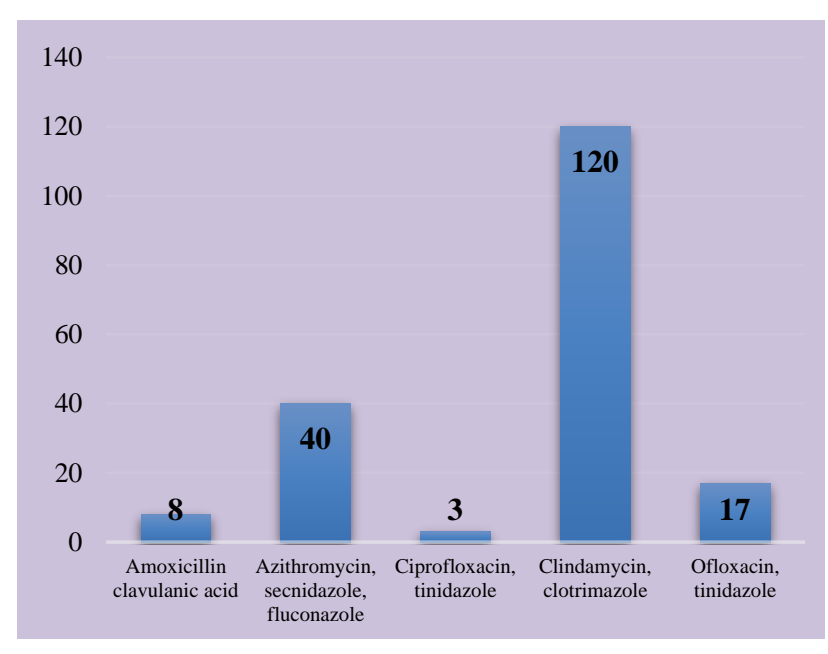

Figure 2: Number of different FDCs prescribed in anti-infectives.

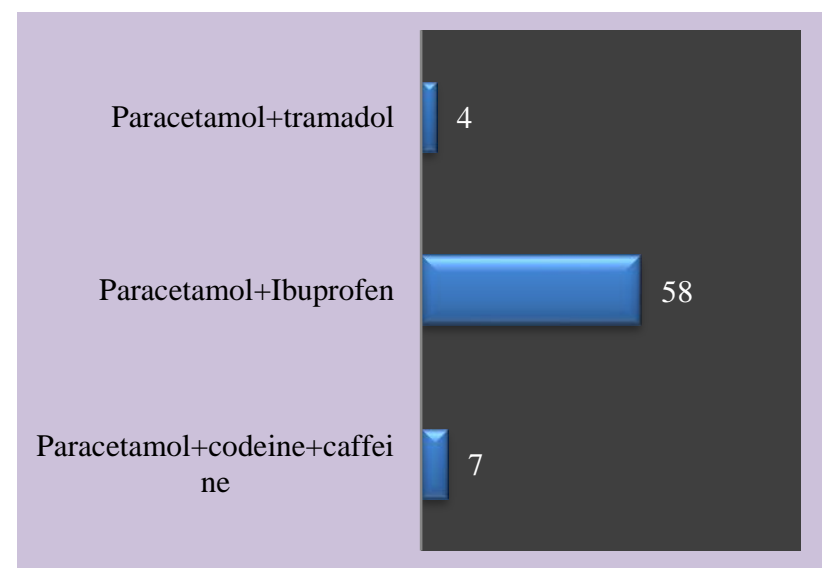

Figure 3: Number of FDCs prescribed in nervous system.

In the anti-infective class of drugs, the most common FDCs prescribed were combinations of clindamycin+clotrimazole (63.82\%), followed by combination of Azithromycin+secnidazole+ fluconazole $(21.27 \%)$ and ofloxacin+tinidazole $(09.04 \%)$ as shown in the Figure 2.

Among drugs affecting the Nervous system combination of Paracetamol + ibuprofen was the most commonly prescribed FDC as shown in Figure 3.

No FDCs belonging to systemic hormonal preparations, cardiovascular system and antiparasitic group were used. Approximately $20 \%$ of the FDCs are currently banned and that list is shown in Table 3.

Table 3: FDCs prescribed in the study which are currently banned.

\begin{tabular}{|lll|}
\hline ATC class & FDC & $\begin{array}{l}\text { No of } \\
\text { prescriptions }\end{array}$ \\
\hline Anti-infective & $\begin{array}{l}\text { Azithromycin, } \\
\text { secnidazole, } \\
\text { fluconazole }\end{array}$ & 40 \\
& $\begin{array}{l}\text { Clindamycin, } \\
\text { clotrimazole }\end{array}$ & 120 \\
\hline Musculoskeletal & $\begin{array}{l}\text { Mafenamicacid, } \\
\text { paracetamol }\end{array}$ & 1 \\
\hline & $\begin{array}{l}\text { Mefenamic acid, } \\
\text { dicycloverine }\end{array}$ & 27 \\
\hline Nervous system & $\begin{array}{l}\text { Paracetamol, } \\
\text { codeine, caffeine }\end{array}$ & 7 \\
\hline & $\begin{array}{l}\text { Paracetamol, } \\
\text { tramadol }\end{array}$ & 4 \\
\hline Respiratory & $\begin{array}{l}\text { Diphenhydramine, } \\
\text { ammonium } \\
\text { chloride, sodium } \\
\text { citrate, menthol } \\
\text { system }\end{array}$ & 1 \\
\cline { 2 - 3 } & $\begin{array}{l}\text { Doxylamine, } \\
\text { pyridoxine }\end{array}$ & 36 \\
\hline Total & 236 \\
\hline
\end{tabular}




\section{DISCUSSION}

The Indian medicine market has become the world leader of FDCs and number of estimated FDCs in India is over 6000. Numerous studies have shown violation of scientific merits without adequate justification among available FDCs. There is no database of currently available FDCs in the market, their sales turnover and use pattern. ${ }^{6}$ Polypharmacy is very common and there is an increasing inclination to combine drugs, more often than not without a sound rational basis for doing so. ${ }^{7}$

This is a prospective observational study done in a tertiary care hospital done using prescriptions of patients attending OBG OPD during the study period.

Authors have found that a total of $41 \%$ drugs were FDCs. A study conducted by Biswadeep das MD et al, had 64.8\% as FDCs which is high compared to our study. ${ }^{8}$ Highest number of FDCs belonged to alimentary system followed by drugs belonging to anti-infective, Blood and blood forming organs and respiratory system. In a study done in various clinical departments by Deepak et al, percentage of FDCs prescribed were $64.29 \%$ and most of them belonged to antimicrobial class. ${ }^{9}$ Vitamin D3 and Calcium combination was the most commonly prescribed FDC. This is probably explained by the use of this FDC to prevent osteoporosis IN POST-MENOPAUSAL WOMEN. This study finds that FDCs constitute a significant portion of drugs that are prescribed in the department of OBG.

Many of these drugs were recently banned combinations because of their irrationality. ${ }^{10}$ Wide scale studies on FDC usage in various clinical departments to help build national database may go long way in promoting rational drug use.

Funding: No funding sources

Conflict of interest: None declared

Ethical approval: The study was approved by the Institutional Ethics Committee

\section{REFERENCES}

1. WHO Expert Committee on Specifications for Pharmaceutical Preparations: thirty-ninth report. (WHO technical report series; 929); 2005.
2. World Health Organization. Regulation of fixed-dose combination products. WHO Drug Information. 2003;17(3). Available at: http://apps.who.int/medicinedocs/en/d/Js4955e/7.htm 1 accessed on 14 September 2018

3. Gautam CS, Saha L. Fixed dose drug combinations (FDCs): rational or irrational: a view point. Bri $\mathrm{J}$ Clinical Pharmacol. 2018;65(5):795-6.

4. DD news. Gove bans 328 fixed dose combination drugs with immediate effect. Available at: http://ddnews.gov.in/health/govt-bans-328-fixeddose-combination-drugs-immediate-effect accessed on $15 / 09 / 2018$

5. Jain S, Upadhyaya P, Goyal J, Kumar A, Jain P, Seth $\mathrm{V}$, et al. A systematic review of prescription pattern monitoring studies and their effectiveness in promoting rational use of medicines. Perspectives in Clinical Research. 2015;6(2):86-90.

6. Gupta YK, Ramachandran SS. Fixed dose drug combinations: Issues and challenges in India. Indian J Pharmacol. 2016;48:347-9.

7. Eesha BR, Shanbhag T, Adiga MNS, Shenoy S. Prescription Pattern of Fixed Dose Drug Combination in Tertiary Care Hospital: An Evaluation Study. Biomedical Research. 2009;20(3):176-9.

8. Das B, Sarkar C, Datta A, Bohra S. A study of drug use during pregnancy in a teaching hospital in western Nepal. Pharmacoepidemiol Drug Saf. 2003;12(3):2215.

9. Upadhyay D, Singh A, Joshi H, Agarwal M, Katyal R. Study of Prescription Patterns of Fixed Dose Combinations Prescribed by Medical Interns. IJBR 2016;7(9):624-8.

10. The gazette of India. Available at: http://egazette.nic.in/(S(03j4qcdv53fnnkbtre4tpsyq))/ EnhancedSearch.aspx. Accessed 16 October 2018.

Cite this article as: Manjunatha $\mathrm{CH}$, Rohith $\mathrm{V}$, Maheshwari R, Topno I. Prescription pattern of fixed dose drug combinations in obstetrics and gynecology department of a tertiary care hospital in Puducherry, India: an observational study. Int J Basic Clin Pharmacol 2018;7:2122-5. 